\title{
Look into my Eyes
}

\author{
Tara Higgins, Moore College of Art and Design, USA
}

Keywords: Design, Feminism, Leather, Silk

An androgynous ensemble intended to evoke the questions of social constructs created by western civilization and the objectification of women in a patriarchal society. The breast is a symbol of a woman's power to create life and its primary biological purpose is to nurture the young. So, why does an exposed female chest generate a reaction of shame by the individual and become a sexual object to the male counterpart? How is it that indigenous tribes see the female breasts for what they are while certain cultures having a tendency to sexualize them? It is the human condition to want what cannot be seen; hidden proves to be enticing. The garment is meant to expose that perception and challenge the viewer to see past the sexual aspect of the breast.

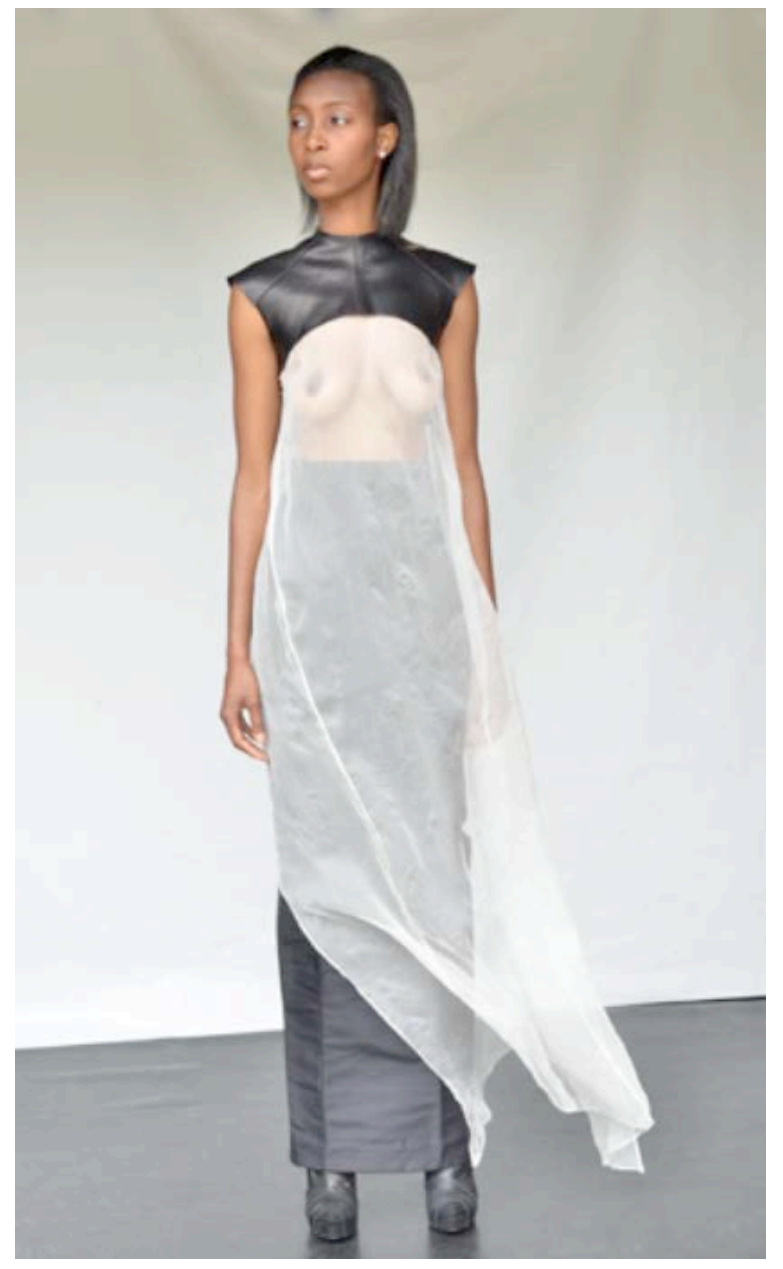

The intent of these garments is to illustrate those constructs by creating a three-piece ensemble that highlights and frames the breast in an unconventional manner and to break the status quo of what is deemed appropriate in today's society. In ancient times, clothing was merely a necessity to stave off the harsh elements of the environment. As civilizations evolved, attitudes toward nudity varied with the additions of religious puritanical belief systems and social classes. Today, many tribal women in warmer climates freely walk about topless, unbound by the social constraints of our own modern day society. The female form is viewed as a natural, everyday part of life and an exposed nipple no different than the male version (Cavendish, 2010, p.575). The significance lies in the fact that men are not hardwired to relate breasts to the act of sex; it is a learned response carried out through society. In the United States, women have been shamed for not only showing too much skin but punished by law for breastfeeding in public, for doing what they were naturally intended to do. Who has the right to say what they are for, when and where they can be seen, and by whom? For far too long, women's bodies have been used to 
reflect male dominance by becoming an object for oppression and repression.

The goal was to encapsulate an androgynous feeling as a whole look while individually the garments by themselves would represent a different element. Research was incorporated to establish a starting point and a digital mood board was put together of various images that embodied androgyny and feminist modern art. Draping muslin prototypes and transferring them to flat patterns developed each of the pieces. The garments were fitted to a model and altered to her measurements. The long black silk pencil skirt sits high on the waist and accentuates the lower half of the body. It is constructed in a double-faced dupioni silk with princess panels that were edge stitched to create a three-dimensional seam and geometric contouring. A gunmetal exposed zipper brings an element of surprise to a classic feminine silhouette. A distressed fulllength organza sheath with an open back is worn over the skirt. Lastly, a cropped leather overlay is placed over the décolleté with a contoured cutaway front that emphasizes the chest through the sheer organza. The leather overlay is made from a medium weight black lambskin with high armholes and neckline. The shoulders are slightly capped to exaggerate a sense of masculinity. The back incorporates elements of the tuxedo as the shape mirrors the quintessential coat tails seen in tailoring.

Visually, the garments work together by creating juxtapositions between hard and soft, translating them into a metaphorical balance between masculine and feminine. The skirt embodies the female aspect of the ensemble; creating an archetypal hourglass shape by using shapely princess seams to emphasize the hips. The sheath represents the veil of society that shields a woman's right to choose how she represents her own body. The slightly distressed surface texture symbolizes the flaws within the social order. The leather overlay signifies the structured rigidity of a male and the weight resting on a woman's shoulders to the pressures of trying to conform to a patriarchal culture. An ensemble symbolizing a woman's right to wear what she pleases while boldly challenging society's concept of what is appropriate fashion.

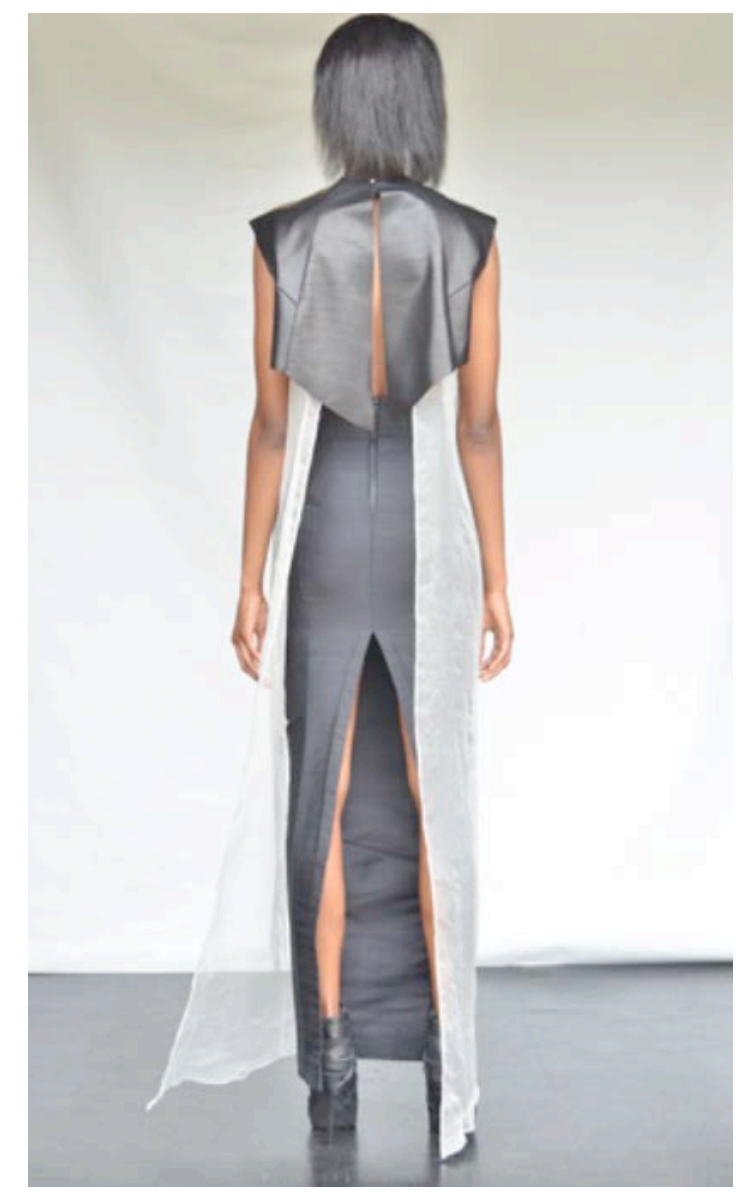

Cavendish, M. (2010). Sex and Society (p. 960). New York, NY: Cavendish Square Publishing. 